\title{
Epidural Hematoma Formation Following Neuraxial Interventional Pain Management Procedures. Have We Even Begun to Comprehend the Mechanisms and Risk Factors?
}

\author{
Kenneth D. Candido, MD
}

Epidural hematoma $(\mathrm{EH})$ development is a somewhat rare but catastrophic consequence of procedures performed about the central neuraxis, including interlaminar, caudal, and transforaminal epidural injections. While historically it has been believed that the vast majority of these cases occur in individuals taking anticoagulation medications (1), we have begun to realize that some individuals may develop an $\mathrm{EH}$ who have no apparent risk factors whatsoever. In the Anesthesia Closed Claims Project, $90 \%$ of claims for neuraxial hematoma were for patients who were being treated using anticoagulation drugs; all of these cases resulted in long-term, severe, and permanent injuries, largely due to a significant delay in diagnosis and treatment after the first appearance of clinical signs and symptoms (1). Much of our knowledge is derived from large surveys such as these, and in patients who have undergone epidural catheterization for obstetrical and surgical anesthetic procedures. However, as this inaugural issue of Interventional Pain Management Reports attests to, the incidence of an $\mathrm{EH}$ developing following pain management procedures, while still unknown, appears to be on the rise and potentially underreported (2-5).

Kenneth D. Candido, MD

Editor in Chief, Interventional Pain Management Reports

Chairman, Department of Anesthesia

Advocate Illinois Masonic Medical Center

Professor of Clinical Anesthesiology and Surgery

University of Illinois College of Medicine-Chicago

Address for correspondance: Department of Anesthesiology and Pain Management, Advocate Illinois Masonic Medical Center, 836 Wellington Ave., Chicago, IL 60657

E-mail: kdcandido@yahoo.com
The mechanism of injury remains somewhat unknown when an EH develops. Bleeding from an epidural vein may occur with needle or catheter insertion, but this is typically self-limiting. However, arterial bleeding may lead to impaired perfusion and mechanical compression of the spinal cord and exiting spinal nerve roots. Compression secondary to bleeding is not likely due to venous etiologies but more commonly to arterial bleeds, because cerebrospinal pressure typically exceeds central venous pressure in a supine patient and hence venous bleeding is less likely to result in the accumulation of large masses of blood, even in the face of anticoagulation. The pressure that is generated in the epidural space depends upon the capacitance of the epidural space. Neurological signs and symptoms secondary to an $\mathrm{EH}$ are atypical in the presence of normal coagulation. While the true incidence remains somewhat obscure, best guesses place the incidence of an $\mathrm{EH}$ developing in the surgical or obstetric (OB) patient undergoing either single-shot or continuous catheter epidural cannulation as somewhere in the range of 1:150,000 (6).

Early diagnosis and intervention are essential to minimize long-term adverse outcomes when an $\mathrm{EH}$ occurs. Recently, newer anticoagulants and antiplatelet drugs have been introduced giving rise to new challenges in the management of patients who require these to minimize stroke risk and myocardial infarction risk (7-9). Many more of these patients are presenting to our respective interventional pain management centers every day, as the medical community continues to treat elderly "baby-boomers" at an exponential rate. More and more individuals seeking our care and management and who are potential candidates for epidural injections and spinal cord stimulators, present to us each day. It is imperative that we have a high index of suspicion and low thresh- 
old trigger for evaluating the patient who recently had such a procedure and who complains of increasing spinal pain; lower extremity weakness or increasing sensory loss; or bowel and bladder incontinence, as these may all be harbingers of a central compressing lesion from an $\mathrm{EH}$ (2-5). Rapid surgical intervention and evacuation within a somewhat arbitrary time period of 12 hours has been strongly recommended to minimize the likelihood of permanent injury due to impaired perfusion and mechanical compression.

What are the well known and emerging risk factors for the development of an $\mathrm{EH}$ following neuraxial pain management procedures, aside from the obvious association with anticoagulation use? While the answer to this remains somewhat obscure, what we do know now is that individuals with pre-existing neurological conditions may be at risk, even in the absence of anticoagulant use (10). What about the presence of low platelets? And, if this is a risk factor, what is the "absolute acceptable value" to consider before performing a neuraxial procedure? While this again remains unanswered, some reassuring data from the obstetrical population would suggest that epidural catheterization in women with less than 100,000 platelets may not predispose them to develop an $\mathrm{EH}$. In one study of 20,244 OB patients, $1.8 \%$ of whom had low platelets (368 total), there were no EH cases (11). Other data have found precisely the same thing (12); perhaps we need to defocus on relative thrombocytopenia as a major risk factor to developing an $\mathrm{EH}$. One very large review (The Nationwide Inpatient Sample) of 3,703,755 epidural analgesics conducted from 1998 through 2010 noted the incidence of epidural hematoma to be $0.6 / 100,000$ following catheterization in the $\mathrm{OB}$ population, but $18.5 / 100,000$ in non-OB patients. Suggested risk factors for $\mathrm{EH}$ development included patients having vascular surgery, epidurals performed in teaching centers, and a higher comorbidity score (13). Patients developing an $\mathrm{EH}$ had a 12 times higher mortality rate than those who had similar procedures using epidurals, but who did not develop an $\mathrm{EH}$, further emphasizing the catastrophic consequences of this condition developing. Another study of epidural catheter use in a non-OB group of 5,083 patients found an incidence of $\mathrm{EH}$ of $1: 5,083(0.02 \%)$, consistent with the above results (14).
What about the use of aspirin (ASA) alone, without concomitant inclusion of other nonsteroidal anti-inflammatory drugs (NSAID)? There were no definitively reported cases of $\mathrm{EH}$ found in patients chronically consuming both low- and conventional dose aspirin who underwent epidural block (15), and while this may appear somewhat reassuring, recently it has been reported that 2 patients consuming ASA alone developed an EH when their trial spinal cord stimulator leads were taken out, further emphasizing the role of procedural trespass as a possible contributing factor to $\mathrm{EH}$ development (16). Still, it remains imperative, but not always practical to identify those who have abnormal coagulation parameters (clinical history may be the best predictor), because the risk of $\mathrm{EH}$ in those individuals undergoing epidural catheterization is about 1:315 (17). Furthermore, while either ASA alone or NSAID use alone may be somewhat safe, combination therapy (NSAIDs plus fluoxetine, fish oil, vitamin $\mathrm{D}$, etc.) may contribute to $\mathrm{EH}$ formation as noted in case reports following cervical epidural interlaminar procedures $(3,18)$. And, while we might assume that an EH occurs at the site of a neuraxial needle puncture or catheter insertion, there is at least one report of a distant thoracic bleed occurring contemporaneous to a lumbar epidural steroid injection in a patient with no apparent risk factors besides spinal stenosis (19). A major conundrum occurs when an $\mathrm{EH}$ appears spontaneously, albeit contemporaneously, in a patient not on anticoagulation therapy $(20,21)$, or in one who formerly used drugs like clopidogrel but who stopped it within the suggested timing framework promoted by the major societies of regional anesthesia and pain management (22). Do these outliers change the way we proceed in the face of former use of these drugs, or do we consider these conditions to be random chance events?

This inaugural issue of interesting case reports in interventional pain management should help to increase our awareness of the potential that can occur for an EH to develop, even in the best hands and under the best of circumstances. Preparation never ceases; awareness is paramount; a high index of suspicion is key to identifying both those who present unique risks, a priori, as well as alerting us as to what steps should be taken when one presents with signs and symptoms of an impending neurological calamity. 
Epidural Hematoma Following Neuraxial IPM Procedures

\section{REFERENCES}

1. Kent CD, Stephens LS, Posner KL, Domino KB. What adverse events and injuries are cited in anesthesia malpractice claims for nonspine orthopaedic surgery? Clin Orthop Relat Res 2017; Mar 2, (Epub Ahead of Print).

2. Manchikanti L, Malla Y, Benyamin RM, Hirsch JA. Prevalence of epidural hematoma following cervical epidural injections in interventional pain management settings: Literature review with two case reports. Interventional Pain Management Reports 2017; $1: ?$

3. Jenkie EJ, Benyamin RM, Manchikanti L. Fish oil as a potential contributor to epidural hematoma following cervical epidural steroid injection: A case report and focused literature review. Interventional Pain Management Reports 2017; 1:?.

4. Swicegood JR, Manchikanti L, Benyamin RM, Hirsch JA. Two cases of acute epidural hematoma formation after cervical interlaminar epidural steroid injections. Interventional Pain Management Reports 2017; 1:?.

5. Swicegood JR, Manchikanti L, Benyamin RM, Hirsch JA. A report of acute thoracic epidural hematoma after interlaminar epidural injection. Interventional Pain Management Reports 2017; $1: ?$.

6. Horlocker TT, Wedel D, Benzon H, Brown DL, Enneking FK, Heit JA, Mulroy MF, Rosenquist RW, Rowlingson J, Tryba M, Yuan CS. Regional anesthesia in the anticoagulated patient: Defining the risks (the second American Society of Regional Anesthesia Consensus Conference on Neuraxial Anesthesia and Anticoagulation). Reg Anesth Pain Med 2003; 28:172-197.

7. Manchikanti L, Malla Y, Wargo BW, Cash KA, McManus CD, Damron KS, Jackson SD, Pampati V, Fellows B. A prospective evaluation of bleeding risk of interventional techniques in chronic pain. Pain Physician 2011; 14:317-329.

8. Manchikanti L, Benyamin RM, Swicegood JR, Falco FJE, Datta S, Pampati V, Fellows B, Hirsch JA. Assessment of practice patterns of perioperative management of antiplatelet and anticoagulant therapy in interventional pain management. Pain Physician 2012; 15:E955-E968.

9. Manchikanti L, Falco FJE, Benyamin RM, Caraway DL, Kaye AD, Helm II S, Wargo BW, Hansen H, Parr AT, Singh V, Swicegood JR, Smith HS, Schultz DM, Malla Y, Hirsch JA. Assessment of bleeding risk of interventional techniques: A best evidence synthesis of practice patterns and perioperative management of anticoagulant and antithrombotic therapy. Pain Physician 2013; 16:SE261-SE318.

10. Tseng WC, Wu ZF, Liaw WJ, Hwa SY, Hung NK. A patient with postpolio syndrome developed cauda equine syndrome after neuraxial anesthesia: A case report. J Clin Anesth 2017; 37:4951.

11. Bernstein J, Hua B, Kahana M, Shaparin N, Yu S, DavilaVelazquez J. Neuraxial anesthesia in parturients with low platelet counts. Anesth Analg 2016; 123:165-167.

12. Goodier CG, Lu JT, Hebbar L, Segal BS, Goetz L. Neuraxial anesthesia in parturients with thrombocytopenia: A multisite retrospective cohort study. Anesth Analg 2015; 121:988-991.

13. Rosero EB, Joshi GP. Nationwide incidence of serious complications of epidural analgesia in the United States. Acta Anaesthesol Scand 2016; 60:810-820.

14. Kang XH, Bao FB, Xiong XX, Li M, Jin TT, Shao J, Zhu SM. Major complications of epidural anesthesia: A prospective study of 5083 cases at a single hospital. Acta Anaesthesiol Scand 2014; 58:858-866

15. Vela Vasquez RS, Pelaez Romero R. Aspirin and spinal haematoma after neuraxial anaesthesia: Myth or reality? Br J Anaesth 2015; 115:688-698.

16. Giberson CE, Barbosa J, Brooks ES, McGlothlen GL, Grigsby EJ, Kohut JJ, Wolbers LL, Poree LR. Epidural hematomas after removal of percutaneous spinal cord stimulator trial leads: Two case reports. Reg Anesth Pain Med 2014; 39:73-77.

17. Gulur P, Tsui B, Pathak R, Koury KM, Lee H. Retrospective analysis of the incidence of epidural haematoma in patients with epidural catheters and abnormal coagulation parameters. $\mathrm{Br} J \mathrm{An}$ aesth 2015; 114:808-811.

18. Chien GC, McCormick Z, Araujo M, Candido KD. The potential contributing effect of ketorolac and fluoxetine to a spinal epidural hematoma following a cervical interlaminar epidural steroid injection: A case report and narrative review. Pain Physician 2014; 17:E385-E395.

19. Shanthana H, Park J. Acute epidural haematoma following epidural steroid injection in a patient with spinal stenosis. Anaesthesia 2011; 66:1365-2044.

20. Loomba V, Kaveessar H, Dwivedi S. Paraplegia after thoracic epidural steroid injection. Anesth Analg Case Rep 2016; 7:118121.

21. Alkhudari AM, Malik CS, Rahman A, Penmetcha T, Torres M. Epidural hematoma after routine epidural steroid injection. Surg Neurol Int 2016; 7:55.

22. Benyamin RM, Vallejo R, Wang V, Kumar N, Cedeno DL, Tamrazi $A$. Acute epidural hematoma formation in cervical spine after interlaminar epidural steroid injection despite discontinuation of Clopidogrel. Reg Anesth Pain Med 2016; 41:398-401. 
IPM Reports

IPM Reports Vol. 1, No. 1, 2017 